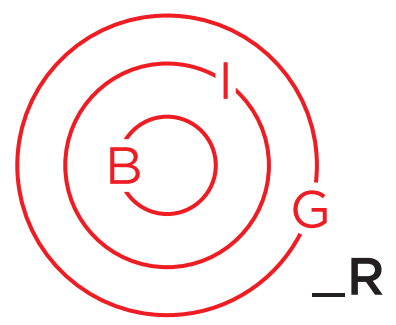

FILM REVIEW

\title{
Kameradschaft (1931): Representing Solidarity Beyond Borders in Face of Disaster
}

\author{
Eric Rigaud ' and Aurélien Portelli ${ }^{i}$
}

\author{
Kameradschaft (1931) \\ Director: G.H. Pabst
}

\begin{abstract}
Kameradschaft ("Camaraderie" in English), a 1931 film directed by G.H. Pabst, focuses on the participation of German miners rescuing French victims of a gas explosion deep inside a mine located at the border between France and Germany. The 1931 film is set after the Great War (WWI), but it was inspired by the 1906 mining disaster in Courrières, where 1,200 miners died due to a gas explosion and where Belgian and German miners participated in search and rescue operations. The first part of the film describes borders in physical, territorial, and identity terms-such as border crossing checkpoints, lines on the ground, gates, metallic bars underground, and linguistic-cultural differencesbetween French and German miners exploiting the same mine. The mine explosion leads to the intervention of the German rescuers crossing all the borders, from checkpoints to gates and language differences. Once the crisis terminates, authorities restored borders, premising an uncertain future.
\end{abstract}

Borders as representation of distance between two miner communities:

Around the same mine, a French and a German community of miners coexist, separated by a border crossing. Scenes show similarities in miners' activities (digging, fire and gas monitoring, relationships with family) thereby demonstrating that they share the same occupational culture of the mining profession such as work organization, risks, fears, and leisure.

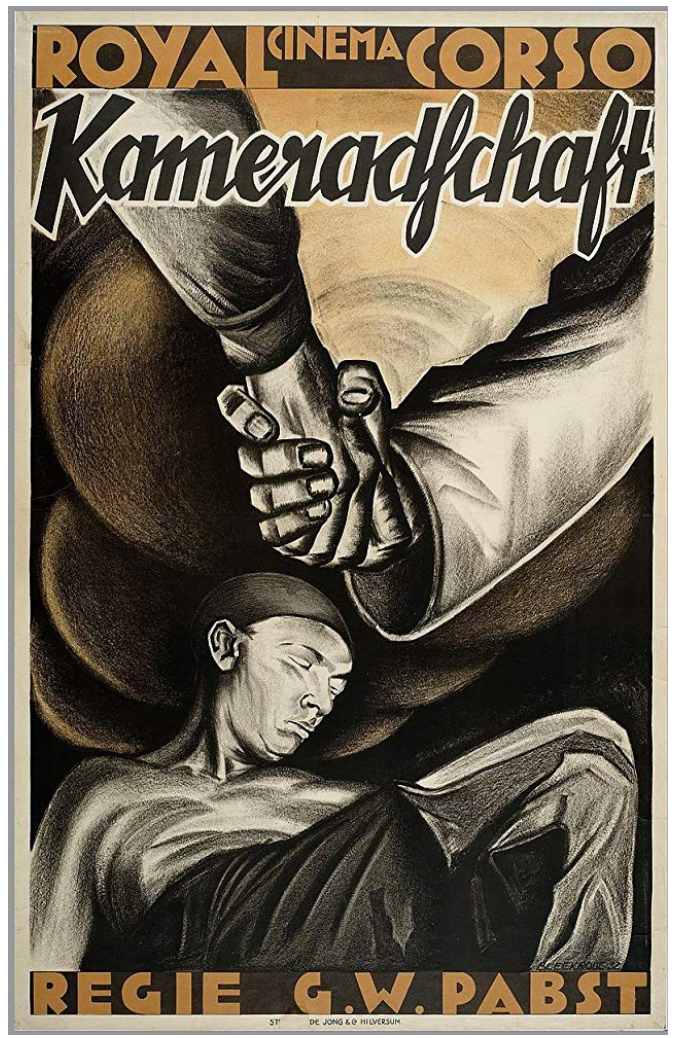

Both French and German adult men are likely to have been soldiers during the Great War. They mostly wished for peace and harmony, portrayed early in the film with two fathers scolding two kids who argue about marbles on both sides of a line traced on the ground by one of the kids, symbolizing the border between the two antagonistic countries.

i Eric Rigaud, Centre of Research on Risks and Crisis Management, MINES ParisTech, Paris-Sciences-etLettres. Contact: Eric.rigaud@mines-paristech.fr

ii Aurélien Portelli, Centre of Research on Risks and Crisis Management, MINES ParisTech, Paris-Scienceset-Lettres. Contact: Aurelien.Portelli@mines-paristech.fr

The authors gratefully acknowledge funding from the German Research Foundation (DFG-FI 2139/3-1 and DFG-SCHU 1189/13-1) and the French National Agency for Research (ANR-16-CE92-0011-01). 
Borders in Globalization Review | Volume 1 | Issue 2 | Spring/Summer 2020

Rigaud and Portelli, "Kameradschaft (1931): Representing Solidarity Beyond Borders"

However, at a dance hall scene in the film, a simple language misunderstanding arouses nationalistic thinking. The food and dancing stop, and the French unite against the Germans, forcing them to leave. With the film set in 1931, during the Great Depression, the unemployed are not allowed to go to the mining entrance portal, and French authorities forbade unemployed Germans to cross the border.

\section{Disaster as a catalyst to collapse of borders:}

Suddenly, inside the mine, an explosion smashes brick walls, initiating the collapse of boundaries separating the two communities.

On the German side, a debate takes place about whether to help the five hundred French miners blocked in the mine. A search and rescue officer tries to convince others to intervene, while others refuse for reasons relating to security, negative stereotypes about the French, and a revengeful spirit after the French occupation of the Ruhr region. A chain curtain, where miners hung their clothes, separated the physical space into two parts. It accentuates the separation between workers. Finally, class solidarity around the risks and occupational similarities of the miners and their families transcend symbolic and national divisions and shatter all borders. The rescue convoy forces open the border crossing. The entrance portal of the mine is opened, and the Germans are welcomed not as invaders but as comrade saviors. Germans turn frustrations from the past into a catalyst for overcoming obstacles deep in the mine. Nevertheless, the disaster and cross-border mutual aid are not sufficient to erase all anchored antagonisms, as illustrated by a scene in which a traumatized French miner re-lives fights into the no man's land he remembered from the Great War when seeing a German rescuer. Affected by the post-traumatic stress, he tries to kills him.

\section{Restoring the border as dark omen:}

Later, the customs barrier remains open. French miners cross the border to celebrate with their saviors. The radiant light of the sequence highlights the euphoria of reunion. The speeches evoke the spirit of solidarity that unites miners beyond national divisions and differences of languages.

By contrast, the last sequence returns to the underground rooms at the border between the two countries. Workers are restoring metallic bars-border barriers deep in the earth-that had been destroyed during the rescue; the exchange of stamped administrative documents restores the relations of order. The authorities pull back and turn off the light, while the camera zooms out, ending on the metallic bars, filmed in long shot. The last image refers to an icy and dehumanized political reality and seems to predict a dark future for European societies.

\section{Interrogation of collective actions during disaster:}

At the beginning of the film, Kameradschaft illustrates conflicts and antagonisms between nations separated by borders in the European context of the thirties, marked by the Great War, the Great Depression and the rise of nationalist tensions. However, the body of the film shows worker solidarity based on occupational and familial similarities amid a risky work environment. The director demonstrates that the Marxist perspective of the working-class based on the spirit of internationalism among workers (underlined by the title of the movie) can be a catalyst for overcoming all the borders during disasters.

Today, climate change, globalization, and technologies increase the exposure of regions to unwanted transboundary events whose complex nature exceeds crisis management capabilities. The situation will be even more critical if the affected region is a borderland and the intensity cross-border cooperation is low.

The film interrogates the nature of the social phenomena that will structure transboundary collective action during disasters. While Marxist perspectives are nowadays dated, it is important to consider how the in-between borderland culture as evoked in the film-a consequence of historical and cultural proximityinduces trust and positive attitudes. 